http://www.doi.org/10.14718/ACP.2021.24.2.15

Reseña bibliográfica

\title{
El deseo y el placer en las neurociencias
}

\author{
David A. Quebradas*
}

Morgado, I. (2019). Deseo y placer: La ciencia de las motivaciones. Editorial Paneta S. A.

Traducir el conocimiento técnico de las neurociencias a un lenguaje más sencillo para el público en general no es una tarea fácil, mucho menos escribir un texto que no sea tan ligero para que un académico o un profesional pierda el interés o tan denso que no pueda ser leído por una persona sin formación en neurociencias, medicina o neuropsicología. No obstante, Ignacio Morgado, director del Instituto de Neurociencia de la Universidad Autónoma de Barcelona, parece haber encontrado hace tiempo el secreto. Esta vez nos sorprende con el texto Deseo y placer: La ciencia de las motivaciones, donde expone un conjunto de ideas sobre el origen del deseo y su relación estrecha con el placer para comprender los dos tipos de motivaciones que tenemos como seres humanos, a saber: la motivación homeostática, que responde a necesidades vitales del organismo como el hambre, la sed y el sueño; y la motivación incentiva, que no responde a una necesidad vital, sino al placer, de manera que nos lleva más allá de las necesidades básicas.

Este libro está constituido por cinco capítulos que llevan al lector desde la definición del placer, el deseo y los distintos tipos de motivación (capítulo uno) en un inicio, pasando posteriormente por la comprensión del sueño y la vigilia (capítulo dos), el hambre y la gesta de alimentos (capítulo tres), y la sed y la homeostasis hidromineral (capítulo cuatro), hasta llevar al lector a uno de los capítulos quizá más controvertidos del texto, el capítulo sobre conducta sexual y parental (capítulo cinco), en el que el autor no tiene miedo de abordar temas polémicos como los relacionados con el por qué somos heterosexuales, homosexuales, bisexuales o transexuales, y los laberintos de la motivación, la conducta sexual y la conducta parental. Para el final, el autor nos deja un epílogo corto que contiene una reflexión obligada y significativa sobre cómo mantener en forma las motivaciones y las ganas de vivir, las cuales pueden perderse en algún momento de la vida debido a la erosión de nuestro cerebro - producto de una enfermedad neurodegenerativa- $\mathrm{o}$ a pequeños cambios en neurotransmisores que afectan el deseo y el placer.

Es importante mencionar que el texto cuenta con pequeños apartados (notas) que permiten que el lector neófito no pierda el hilo de la historia que el autor ha organizado. Así mismo, al final del texto hay un glosario técnico para comprender un amplio conjunto de siglas, conceptos, neurotransmisores, etc., que también serán útiles para los estudiantes de las áreas de la salud. En lo que respecta a los profesionales de medicina, neurociencias, neuropsicología, psicología, hasta filosofía, el texto es un excelente escenario para generar nuevas reflexiones e intuiciones sobe el deseo, el placer y la motivación. Sobre esto último me concentraré a continuación.

\section{La ruta del deseo y la ruta del placer}

Es evidente, de acuerdo con lo expuesto en el libro, que el placer, el deseo y la motivación dependen del buen funcionamiento del cerebro y el cuerpo en general. Cualquier desajuste en los pequeños elementos de nuestro cerebro y cuerpo - neurotransmisores, hormonas u otras moléculaso en algún sistema específico genera toda una reacción en cadena que puede trastornar por completo la motivación de satisfacer las necesidades básicas de dormir, comer y beber, sin contar otras necesidades como la sexual y otras que responden ante todo al placer y no a una necesidad vital.

Como señala tempranamente el autor, los seres humanos somos buscadores de placer, y lo conseguimos de manera inmediata comiendo, bebiendo, descansando, durmiendo, con caricias, besos, satisfaciendo nuestra sexualidad o aliviando el dolor. Así mismo, nos sumergimos en el placer a través de la cognición cuando imaginamos, soñamos, creamos, descubrimos, o cuando conseguimos logros artísticos, académicos, deportivos o de otro tipo. Y todo con la ayuda de nuestro cerebro, que ha hecho del placer no solo un seguro de vida, sino también la mayor motivación para ir más allá de la inercia biológica. Lo último, cabe señalar, gracias al desarrollo de la corteza cerebral; particularmente, de la

Psicólogo de la Universidad del Valle, doctorando en Psicología, asesor de la fundación Parkinson de Colombia, Cali, Colombia. david.quebradas@correounivalle.edu.co 
corteza prefrontal, que nos dio la capacidad de disfrutar aquí y ahora de las consecuencias positivas de nuestras decisiones a futuro (p. 28), y construir un mundo con necesidades más complejas, sagradas y ruines.

El profesor Ignacio Morgado, iniciando el texto, nos brinda una definición sencilla del placer como un sentimiento, entendido como "una percepción consciente agradable y deseable" que se manifiesta no solo en el mundo interno, sino que incluye también posturas y expresiones corporales — p. ej., la relajación de los músculos del rostro, el relamerse los labios, etc.- (p. 29), y que se puede conseguir por diferentes medios; definición en la que se hace evidente la sintonía de sus ideas con el trabajo llevado a cabo por Antonio Damasio (1994), quien define la emoción como un conjunto de cambios corporales, y el sentimiento como la percepción de estos cambios en el escenario del cuerpo que se yuxtapone al estímulo que lo generó.

Teniendo presente la definición anterior, cabe señalar que el placer, como todo sentimiento, cumple una función que, de acuerdo con el autor, sería la de asegurar la satisfacción de las motivaciones homeostáticas, importantes para mantener la vida. Así, el placer de dormir puede garantizar el sueño, el placer de comer nos fuerza a saciar el hambre, y el placer de beber nos impulsa buscar algo para calmar la sed. Adicional a esto, el autor deja claro que el placer puede ir más allá de lo básico, lo necesario, lo homeostático, más allá de la supervivencia, y que el placer mismo permite la búsqueda de lo sagrado, lo científico, lo artístico, lo tecnológico y otros logros que pueden resultar en algunas ocasiones innecesarios, pero igualmente deseados; lo que se conoce como motivaciones incentivas.

Respecto esto último, Morgado llama la atención sobre la capacidad que tiene el placer de separarse de su función primaria y cambiar el orden de los factores, de manera que puede convertirse en una condena cuando las motivaciones incentivas se transforman en necesidades vitales, tal como sucede en las adicciones, donde el placer se vuelve una necesidad vital para el infortunio de muchos. De hecho, el exceso de placer puede alterar los mecanismos corticales y subcorticales que nos permiten buscarlo de manera voluntaria (p. 211), de modo que la satisfacción del placer puede verse dramáticamente reducida por su repetición, lo que a su vez aumenta su búsqueda, pero sin éxito, destruye el equilibrio entre el deseo y el placer, y puede llegar incluso a amenazar la vida misma.

Como señala Ignacio Morgado, "Los placeres crean y mantienen la ilusión de vivir más allá de la inercia biológica, pero para obtenerlos hay que desearlos y buscarlos" (p. 207). Con esto, el autor deja ver que el deseo sería el valor incentivo del placer, el interés de satisfacer las motivaciones que pueden responder a necesidades vitales del organismo como el hambre, la sed y el sueño (motivación homeostática), u otras necesidades que no responden a una necesidad vital, sino al placer mismo (motivación incentiva). De esto modo, el autor completa su diada deseo y placer, que encontrará en el cerebro sus propias rutas de correlación.

Actualmente, es ampliamente aceptado que, aunque los genitales y los labios son zonas erógenas donde parece habitar el placer, el cerebro es la verdadera residencia del placer. De hecho, son múltiples las estructuras del cerebro que hacen posible la experiencia del placer, desde los suburbios del cerebro - estructuras subcorticales como el núcleo accumbens, el pálido ventral y la amígdala — hasta las altas esferas de la corteza cerebral - la corteza prefrontal dorsolateral, orbitofrontal, la región anterior del cíngulo y la ínsula - en la medida en que existen diferentes aspectos del placer a procesar, como "la cantidad, probabilidad, valor subjetivo, utilidad formal y económica y riesgo que puede conllevar, etc.” (p. 35).

Por mucho tiempo se consideró que el sistema mesolímbico dopaminérgico transportaba el neurotransmisor de dopamina desde el área tegmental ventral (ATV) a los núcleos estriados, particularmente la parte ventral, y que esta era la ruta del placer; sin embargo, siguiendo a Ignacio Morgado, lo que ahora se cree es que la dopamina liberada en el núcleo accumbens no genera la sensación de placer, sino que "lo que hace es aumentar el deseo de sentirlo, y esto último promueve la conducta para conseguirlo" (p. 37). De este modo, la dopamina no sería el neurotransmisor del placer, ni el sistema mesolímbico dopaminérgico la ruta del placer, sino del deseo, en tanto que la estimulación del núcleo accumbens no causaría placer, sino que incrementaría su búsqueda, es decir, la motivación para conseguir ese refuerzo positivo. Incluso, se afirma que las realmente responsables del placer parecerían ser las encefalinas y las endorfinas (opiáceos endógenos), y que estas tendrían como vía un sistema de recompensa con mayor velocidad que iniciaría en el nervio vago y continuaría hasta estructuras como el núcleo del tracto solitario o el núcleo parabraquial lateral, trazando "¡la ruta opiácea del placer!" (pp. 39-40).

Sumado a esto, es importante reconocer que tenemos una tendencia natural a repetir las acciones que nos producen una fiesta de opiáceos endógenos en nuestro cerebro, de ahí que el placer no solo motive nuestra acción, sino que además está involucrado en el propio aprendizaje. Así, la relación estrecha entre el placer y el deseo es fundamental para potenciar, modular o suprimir ciertos tipos de comportamientos. No obstante, no es suficiente sentir placer para generar aprendizajes consistentes y mantener nuestras motivaciones; se necesita el primer paso, un pequeño nudge de dopamina para comenzar a buscarlo e identificarlo más y mejor (p. 42). De ahí que cuando los niveles de dopamina 
160

tienen una tendencia a la baja debido a una enfermedad neurológica - p. ej., la enfermedad de Parkinson - u otro tipo de desajuste producto de distintos factores - p. ej., enfermedades físicas, situaciones adversas, trastornos de alimentación, problemas de sueño, etc.-, la motivación por buscar placer se diluye, y el desinterés entra en escena, aniquilando la acción y el aprendizaje pese a conservarse la capacidad de seguir sintiendo placer.

Así, es evidente que cuidar nuestro cerebro es una tarea imperiosa para mantener en buen estado la ruta dopaminérgica del deseo y la ruta opiácea del placer, con el fin de mantener nuestras motivaciones homeostáticas e incentivas en forma, conservando la motivación más importante de todas: la ganas de vivir, nuestro compromiso con la vida misma. Sin duda, después de la lectura del libro podremos entender por qué es importante una alimentación sana, el ejercicio físico de manera regular, un buen sueño, un poco de placer incentivo ( $¡$ sin abusar!), con moderación para evitar el deterioro de los mecanismos cerebrales que nos permiten buscarlo de manera voluntaria, y una buena dosis de variedad y novedad en las actividades del día a día.
Conservar las motivaciones en buen estado será siempre una gran motivación para no "quitarnos la camiseta" en los momentos más difíciles o en la vejez. Por fortuna, la naturaleza nos ha dado una mano para soportar esa búsqueda, el placer.

Para finalizar, solo queda incitar a los lectores a buscar el texto Deseo y placer: La ciencia de las motivaciones, un libro que generará placer tanto a neófitos como a expertos, con definiciones adictivas y reflexiones inesperadas sobre temas complejos de abordar - como las adicciones, la obesidad, la transexualidad, entre otros-, que hoy como profesionales de la salud física y mental debemos asumir desde una mirada más amplia y empática, y, por supuesto, con la ayuda de las neurociencias.

\section{Referencias}

Damasio, A. R. (1994). Descartes' Error: Emotion, Reason, and the Human Brain. G. P. Putnam. 